\title{
POLÍTICAS PÚBLICAS DE RH E A QVT DE SERVIDORES PÚBLICOS: UM CASO EM PERNAMBUCO
}

\section{PUBLIC POLICIES OF HR AND THE QLW OF CIVIL SERVANTS: A CASE IN PERNAMBUCO}

D0I: http://dx.doi.org/10.21714/raunp.v9i2.1491

Danielle Freitas Bezerra Fernandes

Mestre em Comportamento Humano, Gestão de Pessoas e Vantagem Competitiva. Universidade Federal de Pernambuco. E-mail: daniellefbf@hotmail.com

Envio em: Maio de 2016

Aceite em: Julho de 2017

\section{RESUMO}

0 estudo teve como objetivo geral compreender de que maneira as Políticas Públicas de Educação do Estado de Pernambuco influenciam a Qualidade de Vida no Trabalho dos servidores da Gerência Regional de Educação Recife Norte. Optou-se neste estudo pelo modelo de Richard Walton (1973) devido à abrangência e aplicabilidade do referido modelo. No que se refere à metodologia, o estudo adotou a abordagem qualitativa, e 0 método de estudo de caso. 0 campo de estudo foi a Gerência Regional Recife Norte, uma unidade específica da Secretaria de Educação do Estado de Pernambuco, do qual fizeram parte da amostra servidores efetivos, com três anos ou mais na Rede Pública Estadual de Ensino. Para coleta dos dados foram utilizadas observações e entrevistas semiestruturadas. Posteriormente como método de análise dos dados foi utilizado uma análise de conteúdo. Concluiu-se que a Secretaria de Educação do Estado de Pernambuco não possui uma Política Pública de Qualidade de Vida no Trabalho, e foi proposta a implantação de um Programa de QVT, com o objetivo geral de buscar a excelência do Ensino Público através da valorização dos servidores, e após desenvolvimento desse Programa, o mesmo seja transformado em Política Pública.

Palavras-chave: Qualidade de Vida no Trabalho. Políticas Públicas.

\section{ABSTRACT}

The study aimed to understand how the public policies of the State Education in Pernambuco influence the Quality of Life at Work of the Civil Servants of the Regional Recife North Education Management. We chose in this study, the model created by Richard Walton (1973) due to the scope and applicability. With respect to methodology, the qualitative study adopted approach and the case study method. The field of study was the Regional Management North Reef, a secretariat of the specific unit of State Education of Pernambuco, which were part of the sample effective servants with three or more years in the Public Network State Education. To collect data observations semi-structured interviews were used. Later as data analysis method it was used a content analysis. It was concluded that the Secretary of State of Pernambuco Education does not have a Public Policy Quality of Life at Work It was proposed the implementation of a QLW program with the overall objective of seeking excellence in public education through the enhancement of civil servants, and after the development of this program, it is transformed into Public Policy.

Key-words: Life quality at work. Public Policies. 


\section{INTRODUÇÃO}

As crises e competitividades que o mercado atual apresenta, requer que as empresas ofereçam um diferencial nos serviços que destaque a empresa das demais, para que esta possa permanecer no mundo dos negócios. Outra característica importante no mercado é a busca por resultados. Neste contexto, se faz relevante o novo olhar das organizações no que se refere não só as estratégias de negócios como também em relação às habilidades, potencialidades e satisfação dos membros das empresas nas realizações de suas atividades. A consideração de que o bem-estar dos profissionais de uma empresa pode influenciar sua produtividade e competitividade tem feito muitas empresas repensarem suas políticas em gestão de pessoas.

A Qualidade de Vida no Trabalho (QVT) tornou-se uma das grandes preocupações das organizações, devido à relação entre condições adequadas para realização de trabalho e produtividade. Para McGregor (1980), nos anos 50 surgiram às primeiras teorias que associavam produtividade à satisfação do trabalhador. Basicamente, pensava-se que não só era possível unir a produtividade à satisfação, como o bom desempenho do trabalhador lhe proporcionava satisfação e realização (RODRIGUES, 2009, p. 19).

Os estudos sobre qualidade de vida no trabalho tiveram sua origem em empresas da esfera privada. Entretanto, o mundo empresarial não é o único que tem se preocupado, atualmente, em debater temas que envolvem modelos de gestão de pessoas. O setor público vem se defrontando com a necessidade de melhorar os serviços oferecidos à população. Se isso pode ser alcançado via profissionais motivados e valorizados, a qualidade de vida no trabalho assume posição de destaque (IORKORKI; RISSI, 2008, p. 2).

As mudanças e exigências do mercado têm proporcionado impactos, não apenas em empresas privadas como também empresas/órgãos públicos. Existe hoje uma preocupação por resultados, antes não tão relevante. Observam-se mudanças nas Políticas Públicas, principalmente no que diz respeito à valorização do servidor. Ao acompanhar as publicações oficiais das políticas públicas na área da Educação tem-se percebido um investimento no professor quando oferecido diversas formas de aperfeiçoamento, planos de cargos e carreira.

Este trabalho foi focado na Secretaria de Educação do Estado de Pernambuco, mais especificamente na Gerência Regional Recife Norte. A Gerência Regional de Educação Recife Norte, que serviu como campo de estudo, encontra-se localizada no bairro de Santo Amaro, onde é responsável diretamente por 73 Escolas Estaduais e 234 Escolas Particulares, possuindo 139 servidores efetivos e terceirizados vinculados a sua sede, sendo que para este estudo serão considerados os servidores efetivos com 3 anos ou mais na Rede Pública Estadual.

Analisar a qualidade de vida dos servidores da Gerência Regional de Educação Recife Norte, órgão este subordinado ao Governo do Estado de Pernambuco, leva a necessidade de fazer um breve resgate das Políticas Públicas em Recursos Humanos no Brasil e no Estado de Pernambuco, mais especificamente na Secretaria de Educação do Estado de Pernambuco.

Segundo Gomes (1996), o Brasil apresenta diversas lutas trabalhistas, desde o século XIX, até os dias de hoje. Legislações foram sendo criadas no que se refere às relações trabalhistas e desenvolvimento do trabalhador, buscando melhores condições de salário e de trabalho. As políticas públicas no Brasil, em sua maioria, estão relacionadas a lutas trabalhistas, a fatos que agregam valores sociais, econômicos ou organizacionais.

Consideram-se as políticas públicas em recursos humanos, a partir de 1995, através do Ministério da Administração e Reforma do Estado, que fundamentava a necessidade na profissionalização e na valorização do servidor público. Neste sentido, foi proposta a adequação dos recursos humanos, implicando no estabelecimento de uma política voltada para desenvolvimento pessoal, implantação de uma nova política de remuneração, instituição e reorganização de planos de cargos e carreiras, concursos regulares. Realizou ações no sentido do desenvolvimento de recursos humanos, como forma de viabilizar estratégia de reestruturação inovadora da gestão pública (MINISTÉRIO DA ADMINISTRAÇÃO FEDERAL E REFORMA DO ESTADO, 1997).

As Políticas Públicas desenvolvidas pelo Governo do Estado de Pernambuco, a primeira vista, dá a impressão de apresentarem esforços para promover a qualidade no atendimento escolar da população e para a valorização do magistério. Contudo, após uma análise mais apurada da questão, mostra que existe pouca continuidade nas políticas públicas ao longo do período enfocado, percebe-se uma continuidade aparente, que não resiste sequer a projetos de duas gestões subsequentes, ainda que se trate de propostas de governos de um mesmo grupo político partidário (OLIVEIRA et al., 2006). 
A implementação de uma política de recursos humanos estimula a competência e profissionalismo, quando centrada na valorização do servidor através de plano de cargo e carreira, formação continuada e o seu desenvolvimento social, daí a importância de observar e oferecer uma qualidade de vida no trabalho nas instituições.

Diante deste contexto este estudo visa responder a seguinte pergunta de pesquisa: Até que ponto as Políticas Públicas de Recursos Humanos da Secretaria de Educação do Estado de Pernambuco influenciam a qualidade de vida no trabalho dos servidores da Gerência Regional de Educação Recife Norte?

Para responder a esta questão, foram propostos como objetivo geral - identificar de que maneira as Políticas Públicas de Recursos Humanos da Secretaria de Educação de Pernambuco influenciam a Qualidade de Vida no Trabalho dos servidores da Gerência Regional de Educação Recife Norte, sob a luz do Modelo de Walton (1973).

Este estudo tem relevância de pesquisa no contexto científico investigar a Qualidade de Vida no Trabalho dentro do serviço público do Estado de Pernambuco voltado para a educação, como também contribuir aos estudos já realizados sobre Qualidade de Vida no Trabalho, relacionando as Políticas Públicas de Recursos Humanos. A preocupação reside, portanto, em discutir a verdadeira efetividade e contribuição da QVT para o serviço público na educação. Poderá também contribuir para construção de trabalho mais humanizado, que resulte na melhoria das relações interpessoais e na satisfação dos funcionários no ambiente de trabalho. Tendo em vista que através dos resultados práticos, a Secretaria de Educação do Estado de Pernambuco, mais especificamente a Gerência Regional de Educação Recife Norte, foi beneficiada com o resultado da pesquisa e com a proposta de implantação de um Programa de QVT, com o objetivo geral de buscar a excelência do Ensino Público através da valorização dos servidores, e após desenvolvimento desse Programa, o mesmo seja transformado em Política Pública.

\section{FUNDAMENTAÇÃO TEÓRICA}

A temática Qualidade de Vida no Trabalho (QVT) está presente tanto nas organizações como na vida do indivíduo, buscando melhorias nas condições de vida, um melhor bem-estar e satisfação nas atividades exercidas. Para as organizações a QVT tem importante papel na verificação de informações sobre fatores que interferem diretamente na satisfação e motivação pessoal e coletiva, que podem refletir nas estruturas organizacionais e no serviço, também se torna uma ferramenta importante no planejamento estratégico na obtenção de resultados mais eficazes e com maior qualidade. Para os indivíduos a QVT tem relevância quando considerada como forma de compreender o processo do trabalho e seus impactos na vida do trabalhador, tanto na esfera profissional, quer seja pela produtividade ou absenteísmo, quanto na esfera pessoal, quer seja relacionado na vida pessoal, familiar, conflitos internos, doenças dentre outros (MORIN, 2001).

Em 1950, a Qualidade de Vida no Trabalho surgiu como investigação científica, na Inglaterra, através dos estudos de Eric Trist e colaboradores que estudaram um modelo para agrupar o trinômio Indivíduo/ Traba1ho/ Organização. Este estudo originou a abordagem Sóciotécnica, na qual se voltava para os trabalhadores na organização e, ainda, para a saúde, segurança, integração social, estabilidade no trabalho e para a percepção do trabalho como lugar de conquista. Prevalecia a ideia de que os estudos sobre a motivação não deveriam se ater apenas a questões do ambiente e de recompensas externas ao trabalho, mas deveriam abranger também as características da própria tarefa por ele desempenhada (KUROGI, 2008, p. 53).

Vários autores voltados para estudos do comportamento organizacional, promoção da saúde, patologia do trabalho e, mais recentemente programas de qualidade total tem-se dedicado ao exame da qualidade de vida no trabalho (LIMONGI-FRANÇA, 1996, p. 144).

Após revisão bibliográfica, segue abaixo quadro 1 com apresentação resumida de conceitos sobre a QVT a partir de alguns estudiosos: 
QUADRO 1: CONCEITOS EM QUALIDADE DE VIDA NO TRABALHO

\begin{tabular}{|c|c|c|}
\hline AUTOR & DEFINIÇÃO & ÊNFASE \\
\hline Walton, 1973 & $\begin{array}{l}\text { Atendimento de necessidades e aspirações humanas, } \\
\text { calcando na idéia de humanização e responsabilidade } \\
\text { social da empresa. }\end{array}$ & $\begin{array}{l}\text { Humanização e responsabilidade } \\
\text { social, com foco no poder da } \\
\text { empresa. }\end{array}$ \\
\hline Lippitt, 1978 & $\begin{array}{l}\text { Oportunidade para o individuo satisfazer a grande } \\
\text { variedade de necessidades pessoais. }\end{array}$ & $\begin{array}{l}\text { Trabalho, crescimento pessoal, } \\
\text { tarefas completas, sistemas abertos. }\end{array}$ \\
\hline Ginzberg et all,1979 & $\begin{array}{l}\text { Experiências de humanização do trabalho sob dois } \\
\text { aspectos: reestruturação do emprego e grupos } \\
\text { semiautônomos. }\end{array}$ & $\begin{array}{l}\text { Posto individual de trabalho e } \\
\text { processo decisório. }\end{array}$ \\
\hline Drucker, 1981 & $\begin{array}{l}\text { Avaliação qualitativa da qualidade relativa das } \\
\text { condições de vida, incluindo-se atenção aos agentes } \\
\text { poluidores, barulho, estética, complexidade etc. }\end{array}$ & $\begin{array}{l}\text { Responsabilidade social da empresa } \\
\text { nos movimentos sociais, culturais e } \\
\text { políticos. }\end{array}$ \\
\hline Bergeron, 1982 & $\begin{array}{l}\text { Aplicação concreta de uma filosofia humanista pela } \\
\text { introdução de métodos participativos. }\end{array}$ & $\begin{array}{l}\text { Mudança e participação com foco } \\
\text { sociotécnico. }\end{array}$ \\
\hline Werther \& Davis, 1983 & $\begin{array}{l}\text { Esforços para melhorar a qualidade de vida, } \\
\text { procurando tornar os cargos mais produtivos e } \\
\text { satisfatórios. }\end{array}$ & $\begin{array}{l}\text { Valorizações dos cargos, mediante } \\
\text { analise de elementos. } \\
\text { Organizacionais, ambientais e } \\
\text { comportamentais. }\end{array}$ \\
\hline Nadles e Lawler, 1983 & $\begin{array}{l}\text { Maneira de pensar a respeito das pessoas, participação } \\
\text { na resolução de problemas, enriquecimento do } \\
\text { trabalho, melhoria no ambiente de trabalho. }\end{array}$ & $\begin{array}{l}\text { Visão humanista no ambiente de } \\
\text { trabalho. }\end{array}$ \\
\hline Fernandes, 1992 & $\begin{array}{l}\text { Conjunto de fatores que, quando presentes, numa } \\
\text { situação de trabalho, tornam cargos mais satisfatórios } \\
\text { e produtivos, incluindo atendimento as necessidades e } \\
\text { aspirações humanas. }\end{array}$ & Humanização do cargo. \\
\hline Neri, A.M, 1992 & $\begin{array}{l}\text { Atendimento das expectativas quanto a se pensar a } \\
\text { respeito das pessoas, trabalho e organizações, de } \\
\text { forma simultânea e abrangente. }\end{array}$ & Visão holística. \\
\hline Berlanger, 1992 & $\begin{array}{l}\text { Melhorar as condições de trabalho, de modo a } \\
\text { proporcionar aos indivíduos melhores condições de } \\
\text { vida e cargos mais satisfatórios para a própria pessoa, } \\
\text { com reflexos na produtividade. }\end{array}$ & $\begin{array}{l}\text { Condições de vida e cargos mais } \\
\text { satisfatórios }\end{array}$ \\
\hline Camacho, 1995 & $\begin{array}{l}\text { Classificação de programas: orientação familiar, } \\
\text { saúde, ambiente, contato e convívio, evolução/ } \\
\text { desenvolvimento, cultura e desligamento. }\end{array}$ & $\begin{array}{l}\text { Foco motivacional: sobrevivência com } \\
\text { dignidade, segurança, participação, } \\
\text { auto- realização e perspectiva de futuro. }\end{array}$ \\
\hline Dantas, 1996 & $\begin{array}{l}\text { Gerência pela Qualidade Total-GQT: Utilização de } \\
5 \text { s, diagrama de causa e efeito e procedimento da } \\
\text { Qualidade Total nos programas de saúde. }\end{array}$ & $\begin{array}{l}\text { Foco: promoção da saúde: controle, } \\
\text { do colesterol, capacidade física, e } \\
\text { aeróbica, doenças coronárias. }\end{array}$ \\
\hline
\end{tabular}

Fonte: Limongi-França (1996)

Segundo Limongi-França (1996), a construção da Qualidade de Vida no Trabalho ocorre quando se percebe o indivíduo como todo enfoque biopsicossocial. Para ela, todo indivíduo é um complexo biopsicossocial, pois possui potencialidades biológicas, psicológicas e sociais que respondem simultaneamente as condições de vida. Respostas essas onde os níveis são interdependentes e variam de intensidade de um indivíduo para outro (LIMONGI-FRANÇA, 1996, p.146).

\subsection{MODELOS SOBRE QUALIDADE DE VIDA NO TRABALHO}

Walton criou um modelo de avaliação da QVT, nos 
Estados Unidos, em 1973. Para a criação desse modelo buscou em pesquisas e entrevistas identificar fatores de dimensão que podem vir a afetar o trabalhador em seu trabalho. $\mathrm{O}$ autor propôs oito critérios que influenciam a QVT dos colaboradores: compensação justa e adequada, condições de segurança e saúde no trabalho, oportunidade imediata para utilização e desenvolvimento da capacidade humana, oportunidade futura para crescimento contínuo e segurança, integração social na organização de trabalho, o constitucionalismo na organização do trabalho, o trabalho e o espaço total da vida, a relevância social do trabalho na vida (RODRIGUES, 2009).

Hackman e Oldham (1976 apud MORIN, 2001, p. 9-10) propõe um modelo que tenta explicar como as características e interações de um emprego e as diferenças individuais influenciam a satisfação, motivação e produtividade dos trabalhadores. O trabalho tem sentido para uma pessoa quando ela o acha importante, útil e legítimo. Considera que o trabalho apresenta cinco dimensões essenciais: (a) a variedade das tarefas; (b) a identidade do trabalho; (c) o significado do trabalho; (d) a autonomia; (e) o feedback.

Por sua vez Lippitt (1978), tomando por base o modelo de Walton propôs quatro fatores que comporiam a qualidade de vida no trabalho. Esses fatores são o trabalho em si; o indivíduo; a produção do trabalho; a função e estrutura da organização. Lippitt apresenta um modelo considerando a oportunidade para o indivíduo satisfazer a grande variedade de necessidades pessoais (DOURADO, 2007, p. 49-50).

A abordagem de William Westley (1979) classifica e analisa os fatores que afetam diretamente à Qualidade de Vida no Trabalho: econômico, político, psicológico e sociológico. Para Westley, é importante observar os fatores econômicos como: remuneração adequada, benefícios, local de trabalho, carga horária e ambiente externo. Em relação aos fatores políticos, explica como é importante ampliar a segurança no trabalho, a atuação sindical, a liberdade de expressão, a valorização do cargo e o relacionamento com a chefia. Sobre o fator psicológico, recomenda que se deva abordar o nível de desafio, de desenvolvimento pessoal e profissional, a criatividade, a auto-avaliação, a variedade e a identidade da tarefa. E quanto aos aspectos sociológicos, deve-se considerar a participação nas decisões, à autonomia, o relacionamento interpessoal, o grau de responsabilidade, pois, assim como o valor pessoal, possuem grande importância na qualidade de vida do trabalhador. A abordagem de Westley se aproxima de Walton quanto enfatiza o lado psicológico e a responsabilidade social da organização em relação às pessoas (KUROGI, 2008, p. 55-56).

Davis e Werther (1983 apud RODRIGUES, 2009: 87) veem a Qualidade de Vida no Trabalho como "afetada por muitos fatores: supervisão, condições de trabalho, pagamento, benefícios e projetos do cargo. Porém, é a natureza do cargo que envolve mais intimamente o trabalhador". Também consideram que podem existir algumas barreiras na implantação de qualquer Programa de Qualidade de Vida no Trabalho. Estas barreiras são compostas pelos próprios empregados, dirigentes ou sindicatos, temendo o efeito de mudanças desconhecidas. Mas, segundo os autores, é preciso vencer o desafio a fim de conseguir uma vida no trabalho de alta qualidade por meio de cargos produtivos e satisfatórios. Acreditam também que os empregadores sentem a necessidade de acompanhar as mudanças ocorridas na sociedade e no mundo do trabalho, no que se refere a ter em suas organizações profissionais qualificados que tenham chances de trabalhar seus potenciais inovadores e criativos (RODRIGUES, 2009, p. 90).

Nadler e Lawler (1983), enfatizam nos seus estudos o sucesso da qualidade de vida no trabalho nas organizações. Após realizarem pesquisas identificaram seis fatores que preveem o sucesso dos projetos de QVT, são: percepção da necessidade, o foco do problema que é destacado na organização, estrutura para identificação e solução de problema, compensações projetadas tanto para os processos quanto para os resultados, sistemas múltiplos afetados e envolvimento amplo da organização (RODRIGUES, 2009, p. 92).

Para Huse e Cummings (1985) "a QVT pode ser hoje definida como uma forma de pensamento envolvendo pessoas, trabalho e organização", enfatiza a qualidade de vida no trabalho e produtividade (RODRIGUES, 2009, p.90). Entendem ainda que, de forma indireta, a QVT pode vir a influenciar positivamente nos resultados da produtividade. Quando o funcionário tiver maior motivação, capacidade e coordenação possuirá maior produtividade.

Após leituras realizadas sobre estudos referentes à QVT, optou-se, neste estudo, por adotar o modelo de Richard Walton (1973) devido à amplitude dos seus oito critérios para o estudo da qualidade de vida no trabalho e, portanto, devido a abrangente aplicabilidade do referido modelo. 


\subsection{MODELO DE WALTON (1973)}

Para Walton (1973 apud FREITAS; SOUZA, 2009, p. 139), a "Qualidade de Vida no Trabalho (QVT) descreve certos valores ambientais e humanos, negligenciados pelas sociedades industriais em favor do avanço tecnológico, da produtividade e do crescimento econômico" (p. 11). Propôs oito critérios, no intuito de fornecer uma estrutura para analisar as características da QVT, assim descritas:

1. Compensação justa e adequada. Os indicadores se referem a salário e jornada de trabalho. Para Walton não existe consenso em padrões objetivos e subjetivos para julgar a compensação adequada (p. 12). A avaliação do trabalho especifica relacionamentos entre o pagamento e os fatores tais como a responsabilidade requerida, treinamento do trabalho e a nocividade de condições de funcionamento. Por outro lado, a compensação justa pode estar associada à capacidade de pagar (empresas lucrativas deveriam pagar mais) e também quando mudanças nas formas de trabalhar ocasionam aumento de produtividade (é justo que os ganhos obtidos sejam divididos com os funcionários envolvidos). Percebe-se que para Walton a "compensação" que se refere ao salário está relacionada à experiência e responsabilidade, e a média de mercado.

2. Condições de Segurança e saúde no trabalho. Os indicadores se referem a ambiente físico seguro, saudável e salubridade. Envolve variáveis como horas razoáveis de trabalho, pagamentos de horas extras requeridas, condições físicas do trabalho que minimizem riscos de doenças relacionadas ao trabalho e acidentes de trabalho, imposição de limite de idade quando o trabalho é potencialmente destrutivo para o bem-estar das pessoas abaixo ou acima de certa idade.

3. Oportunidade imediata para utilização e desenvolvimento da capacidade humana. Diz Walton (1973) que o trabalho "tem tendido a ser fracionado, inábil e firmemente controlado" (p. 13). O autor estabelece cinco requisitos para que haja o desenvolvimento da capacidade humana, afetando a participação, a auto-estima e mudanças no trabalho: (a) autonomia - quando o trabalho permite a autonomia e auto-controle das atividades; (b) habilidades múltiplas - quando o trabalho permite o empregado usar habilidades; (c) informação e perspectiva - está relacionada a obtenção de in- formações significativas sobre o processo total do trabalho e os resultados de sua própria ação, tal que permita o funcionário apreciar a relevância e as conseqüências destas ações; (d) tarefas completas - se o trabalho envolve uma tarefa completa ou é apenas uma parte significativa desta e (e) planejamento - se o trabalho envolve o planejamento e implementação do próprio trabalho.

4. Oportunidade futura para crescimento contínuo e segurança. "Neste item o autor focaliza a atenção na oportunidade de carreira. E é nele que surge uma barreira muitas vezes intransponível: a educação formal, que geralmente é pré-requisito para posições mais elevadas dentro da organização. Para viabilização deste item Walton sugere que se trabalhe com: a aplicação respectiva: a expectativa de usar o conhecimento e as habilidades expandidas e recém-adquiridas em atribuições de trabalho futuro; desenvolvimento: a extensão em que as atividades atuais de alguém contribuam para manter e expandir sua capacidade antes de levá-lo à obsolescência; oportunidades de progresso: a avaliação das oportunidades de progredir em termos organizacionais ou de carreiras reconhecidas pelos semelhantes membros da família ou associados; segurança: a segurança de emprego ou de renda associada ao trabalho do trabalhador".

5. Integração social na organização de trabalho. Walton estabelece alguns indicadores fundamentais para uma integração social no trabalho: $a u$ sência de preconceitos - aceitação do trabalhador por suas habilidades, capacidade e potencial independente de raça, sexo, credo, nacionalidade, estilo de vida ou aparência física; igualitarismo $\neg-$ ausência de divisão de classes dentro da organização em termos de status traduzido por símbolos e/ ou por estrutura hierárquica íngreme; mobilidade - mobilidade ascendente como, por exemplo, empregados com potencial que poderiam se qualificar para níveis mais elevados; grupos preliminares de apoio - grupos caracterizados pela ajuda recíproca, sustentação sócio-emocional e afirmação da unicidade de cada indivíduo; senso comunitário extensão do senso comunitário além dos grupos de trabalho; e abertura interpessoal $\neg$ forma com que os membros da organização relatam entre si suas ideias e sentimentos (apud FREITAS; SOUZA, 2009, p. 140).

6. O constitucionalismo na organização do trabalho. Os indicadores se referem aos direitos garantidos, privacidade e imparcialidade. Está relacionado 
aos direitos e deveres que um membro da organização tem quando é afetado por alguma decisão tomada em relação a seus interesses ou sobre seu status na organização, e a maneira como ele pode se proteger. Os seguintes aspectos são elementos chaves para fornecer qualidade de vida no trabalho: (a) privacidade - direito de privacidade pessoal, por exemplo, não revelando informações do comportamento do empregado fora do trabalho ou de membros da sua família; (b) liberdade de expressão - direito de discordar abertamente da visão de seus superiores, sem medo de represálias; (c) equidade - direito a tratamento igual em todos os aspectos, incluindo sistema de compensação, premiações e segurança no emprego; e, (d) processo justo - uso da lei em caso de problemas no emprego, privacidade, procedimentos de processos e apelações.

7. O trabalho e o espaço total da vida. "Walton afirma que a experiência de trabalho de um indivíduo pode ter efeito negativo ou positivo sobre outras esferas de sua vida, tais como suas relações com sua família". A relação entre o trabalho e o espaço total da vida é visto através do conceito de equilíbrio. Para o autor o equilíbrio tem origem nos esquemas de trabalho, expectativa de carreira, progresso e promoção. $\mathrm{O}$ autor questiona ainda a relação do tempo e energia extras que o trabalhador dedica ao trabalho e as deficiências na situação familiar (apud RODRIGUES, 2009, p. 84).

8. A relevância social do trabalho na vida. "Walton denuncia a forma irresponsável com a qual algumas organizações agem, fazendo com que um número crescente de empregados deprecie o valor de seus trabalhos e carreiras, afetando, assim, a autoestima do trabalhador. A produtividade também parece ter uma relação curvilínea para a maioria das dimensões de vida no trabalho. Tem-se ainda a autonomia crescente, multiplicidade de habilidades etc., não são diretamente proporcionais à QVT. Mas, a satisfação do empregado e a autoestima são derivados destes aspectos do trabalho. Segundo Walton (1973), teríamos um ponto ótimo para produtividade que não seria no momento máximo de QVT percebida pelo trabalhador, mas em sua ascendência. Diz o autor que "os declives particulares das curvas e a relação entre a Qualidade de Vida no Trabalho e as curvas da produtividade variaria de um conjunto de trabalho para outro. Prevê que as mudanças das condições organiza- cionais ocorrerão num passo mais lento do que a do aumento das expectativas do empregado. Esta situação trará uma maior alienação para o trabalhador e somente com uma reestrutura do trabalho, a Qualidade de Vida poderá ser exaltada e as expectativas dos trabalhadores de todos os níveis poderão ser entendidas e satisfeitas (apud RODRIGUES, 2009, p. 85).

Para Mônaco e Guimarães (2000, p. 75), o "Modelo de Walton é o mais amplo, contemplando processos de diagnóstico de Qualidade de Vida no Trabalho, levando em consideração os fatores intra e extra empresa". Desta forma, considera a relação do indivíduo com seu trabalho e sua implicação para a vida do mesmo. Esse modelo apresenta uma ligação entre a dimensão da tarefa e os estados psicológicos que podem interferir nos resultados no trabalho, destaca a análise de cargos ou tarefas em relação às expectativas do trabalhador.

Após estudar alguns modelos de QVT, optar pelo modelo de Walton e considerando o objetivo geral desse estudo, se faz necessário tratar sobre as Políticas Públicas de Recursos Humanos na Educação que será tratada na subseção a seguir:

\subsection{POLÍTICAS PÚBLICAS DE RECURSOS HUMANOS NA EDUCAÇÃO}

As Políticas Públicas em Recursos Humanos no Brasil ocupam a temática estratégica da discussão e implementação de políticas de capacitação e formação do funcionário, políticas salariais, entre outros. Segundo Gomes (1996), uma política de recursos humanos tem como objetivo definir critérios de diagnósticos e elaboração e implantação de programas que visem à preparação do indivíduo para o desenvolvimento de suas atribuições dentro da organização. Preocupa-se com as condições relacionadas à saúde do funcionário e o seu bem-estar (GOMES, 1996, p. 42). Este estudo focou as políticas públicas de recursos humanos voltados para educação, mais especificamente na Secretaria de Educação do Estado de Pernambuco.

Para melhor entendimento das políticas públicas vivenciadas no período de 1975 a 2013, foi elaborado quadro 2 que apresenta resumo da relação dos períodos com as Políticas Públicas da Secretaria de Educação do Estado de Pernambuco implementadas em cada fase: 
QUADRO 2: POLÍTICAS PÚBLICAS DA SEE DO ESTADO DE PERNAMBUCO

\begin{tabular}{|c|c|}
\hline PERIOODO & POLÍTICAS VIVENCIADAS \\
\hline $1975-1982$ & Não se percebeu nenhuma política estruturadora voltada para a profissionalização. \\
\hline $1983-1986$ & $\begin{array}{l}\text { Foram organizados concursos literários, festivais de musicas, salões de arte, pois acreditavam } \\
\text { promover prestígio perante a comunidade. Em termos salariais foram realizadas algumas discussões } \\
\text { sem avanços. }\end{array}$ \\
\hline $1987-1991$ & $\begin{array}{l}\text { Foi direcionada ao aperfeiçoamento dos docentes, através de formação. Referente à política salarial } \\
\text { houveram ganhos para os docentes da pré-escola e das séries iniciais do EF, sua remuneração } \\
\text { passou a ser relacionada com a titulação. }\end{array}$ \\
\hline 1991- 1994 & $\begin{array}{l}\text { A política de valorização do docente não apresentou avanços significativos, tanto no que se refere ao } \\
\text { aperfeiçoamento quanto à remuneração, destacando apenas a realização de concurso público. }\end{array}$ \\
\hline $1995-1998$ & $\begin{array}{l}\text { Apresentou esforços visando o aperfeiçoamento dos docentes como um processo sistemático e } \\
\text { contínuo, como o incentivo aos docentes de cursarem pós-graduação. Houve realização de concurso } \\
\text { para complemento de quadro de professores em todo o estado. }\end{array}$ \\
\hline $1999-2002$ & Prioridade na implementação do Plano de Cargos e Carreiras. \\
\hline $2003-2006$ & A valorização do professor se deu ora pela qualificação, ora pela premiação. \\
\hline $2007-2010$ & $\begin{array}{l}\text { Concurso para professor. Distribuíram } 26 \text { mil notebooks. Adotou bônus por desempenho. Oferecidos } \\
\text { diversos cursos de Pós-graduação (lato Sensu). Foi criado o Núcleo de Assistência ao Servidor (NAS). }\end{array}$ \\
\hline $2010-2013$ & $\begin{array}{l}\text { Continua oferecendo formações nas áreas pedagógicas e gestão. Incentivo aos professores a } \\
\text { fazerem cursos de pós-graduação. }\end{array}$ \\
\hline
\end{tabular}

Fonte: Adaptação autoras

Esta subseção tratou das Políticas Públicas de Recursos Humanos, buscando identificar as Políticas Públicas de RH da Secretaria de Educação do Estado de Pernambuco. No panorama apresentado, percebe-se que as políticas públicas desenvolvidas pela Secretaria estão voltadas para aspectos pedagógicos, desenvolveu ações referentes aos servidores conforme apresentado, porém requer implementar políticas públicas que venham favorecer $\mathrm{o}$ atendimento e $\mathrm{o}$ desenvolvimento do ser humano com ser multidisciplinar, reconhecendo suas mais variadas e amplas necessidades.

Na próxima seção serão apresentados os procedimentos metodológicos que estão relacionados ao problema deste estudo.

\section{PROCEDIMENTOS METODOLÓGICOS}

Os procedimentos metodológicos estão relacionados com o delinear, o modo como se procederá à pesquisa. O pesquisador deve apresentar o conjunto de procedimentos metodológicos que será utilizado para a realização da pesquisa (RODRIGUES, 2006, p. 166).

Como forma de abordagem neste estudo foi utili- zada a pesquisa qualitativa, o método estudo de caso. Tendo em vista que dela faz parte à obtenção de dados descritivos mediante contato direto e interativo do pesquisador com a situação objeto de estudo.

A pesquisa qualitativa é uma atividade situada que localiza o observador no mundo. Consiste em um conjunto de práticas materiais e interpretativas que dão visibilidade ao mundo (DENZIN; LINCOLN, 2007). No caso deste estudo, em que envolvem aspectos subjetivos, como a percepção de servidores a respeito da qualidade de vida no trabalho, este tipo de abordagem parece melhor se adequar.

Godoy (1995) aponta existência de, pelo menos, três diferentes possibilidades oferecidas pela abordagem qualitativa: a pesquisa documental, o estudo de caso e a etnografia. Nesta pesquisa utilizaremos o método do estudo de caso, na medida em que concentraremos a investigação em uma unidade específica da Secretaria Estadual de Educação do Estado de Pernambuco, a Gerência Regional Recife Norte.

Segundo Yin (1989), a preferência pelo uso do Estudo de Caso deve ser dada quando do estudo de eventos contemporâneos, em situações onde os comportamentos relevantes não podem ser manipulados, mas onde é possível se fazer observações diretas e entrevistas sistemáticas. Apesar de ter pontos em 
comum com o método histórico, o Estudo de Caso se caracteriza pela “... capacidade de lidar com uma completa variedade de evidências - documentos, artefatos, entrevistas e observações" (BRESSAN, 2000).

Essas especificidades e considerações sobre o estudo de caso orientaram o desenvolvimento da presente pesquisa, permitindo-nos explorar de forma variada, as dimensões do objeto de investigação dentro de sua realidade histórica e social. O caso selecionado parece-nos ser representativo de outros casos análogos, por considerarmos como típico de um conjunto mais amplo do qual se torna o representante que pode melhor ajudar a estudar como as Políticas Públicas de Recursos Humanos na Secretaria de Educação de Pernambuco influenciam a Qualidade de Vida no Trabalho dos servidores da Gerência Regional de Educação Recife Norte.

A Gerência Regional de Educação Recife Norte, que serviu como campo de estudo, encontra-se localizada no bairro de Santo Amaro, onde é responsável diretamente por 73 Escolas Estaduais e 234 Escolas Particulares, possuindo 95 servidores efetivos na sua sede, fazendo parte da amostra para coleta de dados os servidores efetivos que possuam três anos ou mais na Rede Pública Estadual de Educação. Foi delimitado na amostra os servidores efetivos e o mínimo de anos no serviço público considerando que os mesmos já terem finalizado o estágio probatório e terem vivenciado as políticas desenvolvidas pela Secretaria de Educação do Estado de Pernambuco.

A investigação foi desenvolvida utilizando como coleta de dados observações e entrevistas semiestruturadas. Considera-se que a observação tem um papel essencial no estudo de caso qualitativo, pois é por meio dela que se podem apreender aparências, eventos e/ou comportamentos (GODOY, 2010).

A técnica da observação frequentemente é combinada com a entrevista. A entrevista é um instrumento bastante adequado para obtenção de informações acercam do que as pessoas sabem, creem, esperam, sentem ou desejam, pretendem fazer, fazem ou fizeram, bem como acerca de suas explicações ou razões. Ela permite correlações e esclarecimentos, visando à obtenção de aspectos relevantes ao tema pesquisado. Neste estudo optou-se por utilizar de entrevista semiestruturada, tendo em vista que a mesma tem como objetivo principal compreender os significados que os entrevistados atribuem às questões e situações relativas ao tema de interesse e a compreensão do mundo do entrevistado e as elaborações que ele usa para fundamentar suas opiniões e crenças (GODOY,
2010, p. 134).

Nas entrevistas utilizou-se o roteiro de entrevista, baseado nas oito dimensões do Modelo de Walton (1973) e três perguntas direcionadas a percepção dos servidores sobre a QVT, buscando atender aos objetivos específicos: identificar a percepção dos servidores da Gerencia Regional Recife Norte em relação à qualidade de vida no trabalho e descrever ações desenvolvidas pela Secretaria de Educação do Estado de Pernambuco sobre a Qualidade de Vida no Trabalho.

Posteriormente, uma análise de conteúdo foi utilizada como método de análise dos dados coletados, descrevendo as etapas e analisando as condições que as formatam.

Após, analisar o percurso do processo das leituras, embasamento teórico, observação, entrevistas, foi feita considerações procurando sintetizar os principais achados da pesquisa, levantando questionamentos e proposições que sejam propulsores de novas discussões, como também fornecer a Secretaria de Educação de Pernambuco um diagnóstico sobre a Qualidade de Vida no Trabalho dos funcionários da Gerência Regional Recife Norte a partir das políticas públicas de Recursos Humanos, que proporcione novas práticas mais aderentes à realidade dos funcionários da SEE no que se refere à QVT.

\section{ANÁLISE E DISCUSSÃO}

Este capítulo apresenta a análise dos resultados da pesquisa de campo realizada na Gerência Regional Recife Norte, visando responder à pergunta desse estudo: Até que ponto as Políticas Públicas de Recursos Humanos da Secretaria de Educação de Pernambuco influenciam a qualidade de vida no trabalho dos servidores da Gerência Regional de Educação Recife Norte? Neste sentido, perseguimos responder a cada um dos objetivos específicos.

Inicialmente será apresentado o perfil da amostra e sucessivamente a percepção dos servidores da Gerência Regional Recife Norte referente à QVT.

\subsection{PERFIL DOS RESPONDENTES}

Fizeram parte da amostra dos respondentes 33 servidores efetivos, cujas funções se distribuíram entre o cargo de assistente administrativo educacional, analista educacional, professor técnico até chefias. De uma maneira geral, o maior número dos respondentes foi do gênero feminino. Com faixa etária de 30 a 60 anos. Quanto ao estado civil na amostra a maioria 
dos respondentes é casada. O nível de escolaridade dos respondentes nesta amostra em sua maioria possui nível superior. No que se refere à carga horária em sua maioria os respondentes trabalham com carga horária igual ou superior a 6 horas. Quanto ao tempo de serviço dos respondentes da amostra, que em sua maioria estão entre 20 a 29 anos de serviço público na Secretaria de Educação do Estado de Pernambuco. Esses dados mostram a composição geral dos pesquisados, como primeiro meio de aproximar este estudo das pessoas e das suas realidades de trabalho.

\subsection{A PERCEPCCÃO DOS SERVIDORES DA GERÊNCIA REGIONAL RECIFE NORTE REFERENTE À QUALIDADE DE VIDA NO TRABALHO}

Procurando responder ao objetivo específico "Identificar a percepção dos servidores da Gerência Regional Recife Norte em relação à qualidade de vida no trabalho", alguns questionamentos específicos sobre a percepção dos respondentes no que se refere à Qualidade de Vida no Trabalho foram elaborados e serão discutidos.

Segundo Walton (1973), a dimensão que trata da compensação justa e adequada, os indicadores reportam-se a salário e jornada de trabalho, percebe-se que os servidores efetivos na sua maioria não estão satisfeitos com a relação entre salário recebido e as horas trabalhadas. Outro aspecto ressaltado pelos respondentes foi a questão da falta de uma política de valorização para o magistério. Ao tratar da valorização do profissional no que concerne a remuneração foi possível perceber a partir da pesquisa realizada sobre as políticas públicas de recursos humanos na Secretaria de Educação do Estado de Pernambuco entre os anos de 1975 até 2013, durante diversos quadriênios e diferentes governos, identificou-se que não foi desenvolvida uma política salarial que venha atender as necessidades dos servidores desta Secretaria.

A dimensão da relevância social do trabalho na vida tratada por Walton (1973) estabelece a valorização do próprio trabalho e aumento da autoestima. Nesta dimensão foi ressaltado, pela maioria dos respondentes, que gostam da função e atividade que desenvolvem, tem orgulho do que fazem e sentem contribuir para sociedade. Porém, não demonstram sentimento de orgulho da organização da qual faz parte.

No que se refere à oportunidade de crescimento profissional, foi tratado através da dimensão oportunidade futura para crescimento contínuo e segurança, os respondentes avaliam que na função exercida não possuem oportunidades de ascensão profissional, através de cargos, pois são poucos e as gratificações não compensam assumir chefias. Verifica-se que a forma de ofertar oportunidade para o crescimento contínuo adotado pela Secretaria de Educação se dar através de formações e cursos de especializações, faltando desenvolver uma política educacional que possibilite aos servidores efetivos uma oportunidade de crescimento e desenvolvimento profissional para todos os cargos existentes.

Outra dimensão apresentada por Walton (1973) é a oportunidade imediata para utilização e desenvolvimento da capacidade humana, nesta dimensão os respondentes foram questionados se para desenvolvimento de suas atividades haveria espaço para intervenções ou participação nas decisões, como também possuíam autonomia para decidir algo relativo às suas tarefas. Os respondentes, em sua maioria, afirmam realizar intervenções quando necessário como também participa de decisões, mas ressaltam que estas são respaldadas em leis e decretos, não possuindo uma autonomia plena.

A respeito de outra dimensão, as condições de segurança e saúde no trabalho, os indicadores se referem ao ambiente físico seguro e saudável. Os respondentes de maneira geral consideram que o ambiente não está adequado para o desenvolvimento das atividades, pois é considerado pequeno tornando as salas barulhentas e dificultando no desenvolvimento das atividades.

$\mathrm{Na}$ dimensão integração social na organização de trabalho, segundo Walton (1973), trata a natureza dos relacionamentos pessoais permitindo investigar o relacionamento entre os pares do mesmo setor, com outros setores e com os superiores. Foi possível perceber através das respostas dadas pelos respondentes da pesquisa e das observações feitas no ambiente de trabalho que o mesmo apresenta um ambiente saudável, de cordialidade, parceria, resultando no bom relacionamento entre os servidores, proporcionando bons resultados nas atividades e na satisfação no momento da execução do trabalho.

Outro aspecto relevante a ser tratado é o equilíbrio entre o trabalho e a vida pessoal. Foi possível observar nas respostas que as pessoas entrevistadas possuem equilíbrio entre o trabalho e a vida pessoal, tendo o controle do tempo para não impedir que o trabalho atrapalhe suas atividades pessoais e familiares. 
A dimensão constitucionalismo na organização do trabalho, que segundo Walton (1973), se refere aos direitos garantidos, privacidade e imparcialidade. Percebe-se através das respostas dadas pelos entrevistados que nesta dimensão os direitos são respeitados parcialmente, no que se refere ao horário trabalhado, entre outros, porém não são respeitados quando se trata de uma política salarial justa, licenças prêmios que não são concedidas no momento requerido, um melhor atendimento do plano de saúde dos servidores.

Levando em consideração o estudo de Walton (1973) sobre QVT e suas dimensões, percebe-se que na Secretaria de Educação do Estado de Pernambuco a QVT ainda não está atrelada as Políticas Públicas vivenciadas na Rede Pública Estadual de Ensino do Estado de Pernambuco, e que é reconhecida a necessidade de desenvolver uma política de QVT para o servidor, considerada como fundamental para mudanças nas condições de trabalho e na qualidade de vida no trabalho.

\section{CONCLUSÃO}

O objetivo geral desse estudo foi identificar de que maneira as Políticas Públicas de Recursos Humanos da Secretaria de Educação de Pernambuco influenciam a Qualidade de Vida no Trabalho dos servidores da Gerência Regional de Educação Recife Norte. Para isso o estudo foi desenvolvido por etapas para obtermos o resultado final.

Inicialmente foi realizada uma vasta pesquisa sobre Políticas Públicas de Educação do Estado de Pernambuco e a Qualidade de Vida no Trabalho de diversos estudiosos, porém optou-se neste estudo pelo modelo de Richard Walton (1973) pela aplicabilidade do referido modelo que apresenta oito dimensões. Nessa pesquisa identificaram-se as Políticas Públicas de Educação do Estado de Pernambuco no período de 1975 até 2013. Percebeu-se que durante esses anos foram criadas diversas políticas e ações visando à melhoria da qualidade do ensino, mas quando se trata de Política Pública de Recursos Humanos voltada à Qualidade de Vida no Trabalho concluiu-se que até o momento não existe nenhuma Política Pública de Recursos Humanos de QVT na Rede Pública Estadual de Ensino. Foram identificadas algumas ações desenvolvidas, porém muito aquém da necessidade dos servidores, requerendo uma política pública de recursos humanos voltada para melhoria da vida profissional do servidor.
Foi utilizada como forma de abordagem a pesquisa qualitativa, o método estudo de caso, que teve como campo de investigação a Gerência Regional de Educação Recife Norte. A investigação foi desenvolvida utilizando como coleta de dados à observação e entrevistas semiestruturadas, onde foi realizada posteriormente a análise de conteúdo.

Realizaram-se observações e entrevistas semiestruturadas com servidores efetivos da Gerência Regional. Os questionamentos elaborados tiveram como base as oito dimensões apresentadas pelo modelo de Walton sobre QVT, como também se buscou identificar a percepção sobre a QVT nas Políticas Públicas da Educação do Estado de Pernambuco.

A primeira dimensão tratada foi a "compensação justa e adequada" onde se percebe claramente a insatisfação em relação ao salário recebido e as atividades desenvolvidas, sentem que não há uma política de valorização para o magistério. Sugere-se a Secretaria de Educação do Estado de Pernambuco realizar um estudo sobre o quadro de pessoal da Secretaria e elaborar uma proposta de Política Pública de Educação que melhor atenda os servidores no que se refere à questão salarial e melhoria no Plano de Cargos e Carreira.

A segunda dimensão estuda as "condições de segurança e saúde no trabalho", apesar de observar que no campo de estudo as instalações estão em boas condições de limpeza, percebeu-se que o espaço físico não atende mais o número de servidores de todos os setores ali existentes, como também o atendimento ao público em geral, apresentando muitos ruídos e barulho, ocasionando em diversos momentos dificuldades no desenvolvimento das atividades. A Secretaria de Educação precisa realizar adequações nas instalações físicas na Regional e implantar uma Política de Requalificação de Infraestrutura visando ofertar melhores condições de estrutura física para os servidores educacionais. Também necessita de melhores equipamentos como, por exemplo, computadores novos com programas atualizados e oferecimento de internet mais rápida, tendo em vista que atualmente na Gerência Regional em quase todos os casos faz-se necessário o uso desses equipamentos em todos os trabalhos.

A terceira dimensão refere-se a "oportunidade imediata para utilização e desenvolvimento da capacidade humana", a forma de trabalho adotado na Regional condiz com as expectativas do servidor acerca das demandas solicitadas. Nesta dimensão o efeito sobre a satisfação demonstra ser relevante como descrito na anteriormente. 
A quarta dimensão tratou da "oportunidade futura para crescimento contínuo e segurança", percebeu-se que apesar de existir um Plano de Cargos e Carreiras (PCC) na Secretaria de Educação do Estado de Pernambuco, os servidores em sua maioria não se sentem contemplados quando questionados sobre oportunidade de crescimento futuro. A Secretaria de Educação necessita revisar o PCC, analisando as funções existentes e as descrições dos cargos devem ser feitas de forma bem pontual, baseando-se nas reais funções dos servidores.

A quinta dimensão trata da "integração social na organização de trabalho", observa-se que o campo estudado apresenta um ambiente de integração entre os servidores, clima de cordialidade, companheirismo e sentimento de grupo, sendo reconhecido pela maioria dos respondentes.

A sexta dimensão estuda o "constitucionalismo na organização" os respondentes consideraram que seus direitos são respeitados parcialmente, não sendo respeitados quando se trata da política salarial entre outros. Sendo necessário estudo, por parte da Secretaria de Educação, dos direitos dos servidores para identificação dos quais direitos não estão sendo respeitados para que se possa desenvolver ações e programas para garantir os direitos aos servidores.

A sétima dimensão traz "o equilíbrio entre o trabalho e o espaço total na vida", percebeu-se que entre os respondentes, os mesmos possuem esse equilíbrio, conseguem atender de maneira satisfatória as demandas do trabalho e ter tempo para sua vida familiar.

A oitava dimensão do modelo de Walton apresenta a "relevância social do trabalho na vida", a importância que o trabalho tem na vida do indivíduo, observou-se que os respondentes, em sua maioria, exercem sua função como algo ideológico, vocacional. E que os servidores se encontram insatisfeitos e não possuem o sentimento de orgulho da organização da qual faz parte.

Ao concluir o estudo proposto percebeu-se que a Rede Pública Estadual de Ensino não possui uma Política Pública de Qualidade de Vida no Trabalho. A questão salarial foi destacada em diversas dimensões tratadas neste estudo, possuindo espaço central na percepção do servidor sobre a QVT, interferindo em diversos aspectos estudados a partir dos estudos de Walton sobre QVT.

Do ponto de vista teórico a partir das investigações realizadas sobre Qualidade de Vida no Trabalho e a existência de Políticas Pública, foi possível discutir a existência e efetividade da QVT no serviço público na educação. Espera-se que as contribuições apresentadas neste estudo venham despertar novas linhas de pesquisas, principalmente, no que se relaciona a Qualidade de Vida no Trabalho e as Políticas Públicas Educacionais.

\section{REFERÊNCIAS}

BRASIL. Ministério da Administração Federal e Reforma do Estado. A Nova política de recursos humanos. Brasília: MARE, 1997. 52 p. (Cadernos MARE da reforma do estado; c. 11). On Line: Disponível em: <http:// www.planejamento.gov.br/secretarias/upload/Arquivos/publicacao/seges/PUB_Seges_Mare_caderno11. PDF>. Acesso: 20 abr. 2016

BRESSAN, Flávio. O método do estudo de caso. Revista Administração On Line: Prática - Pesquisa Ensino, São Paulo, FEA-USP, v.1, n.1, jan/mar.2000 Disponível em: <http://www.fecap.br/adm_online/art11/ flavio.htm>. Acesso em 21 abr. 2016.

DENZIN, N.K.; LINCOLN, Y.S (Eds). O planejamento da pesquisa qualitativa: teorias e abordagens. 2 ed. Artmed: Porto Alegre, 2007.

DOURADO, Débora Coutinho Paschoal. Qualidade de vida no trabalho: propósitos organizacionais e mecanismos de alienação do homem. 2007. 227f. Tese (Doutorado). Universidade Federal de Pernambuco. CCSA. Administração, 2007.

FREITAS, P. André Luís; SOUZA, G.B. Renata. Um modelo para avaliação da Qualidade de Vida no Trabalho em Universidades Públicas. Revista Sistemas \& Gestão, Rio de Janeiro, v. 4, n.2, p. 136-154, maio/agosto. 2009. 


\section{raUnP}

GODOY, Arilda. S. Introdução à pesquisa qualitativa e suas possibilidades. Revista de Administração de Empresas. v. 35.n. 2 , São Paulo, Mar/Abr. 1995.

GODOY, C.K.; BANDEIRA-DE MELLO, R.; SILVA, A.B. (Org.). Pesquisa qualitativa em estudos organizacionais: paradigmas, estratégias e métodos. 2. ed. São Paulo: Saraiva, 2010.

GOMES, Luciana de Oliveira Miranda. Políticas de Desenvolvimento de Recursos Humanos no Brasil: seus discursos e práticas na Reforma Administrativa do Plano "Brasil Novo". 1996. 103f. Dissertação. Fundação Getulio Vargas. Escola Brasileira de Administração Pública, 1996.

IORKIRKI, Cássia Renata Baruffi e RISSI, Vanessa. Avaliação da qualidade de vida no trabalho: estudo de caso no setor público. 2008. Disponível em: $<$ http://www.imed.edu.br/files/publications/20.pdf $>$. Acesso em 20.04.16

KUROGI, Marcia Sumire. Qualidade de Vida no Trabalho e suas Diversas Abordagens. Revista de Ciências Gerenciais, São Paulo, v. 12, n. 16, p.49-62, 19 dez. 2008.

LIMONGI-FRANÇA, Ana Cristina. Indicadores empresariais de qualidade de vida no trabalho: esforço empresarial e satisfação dos empregados no ambiente de manufatura com certificação ISO 9000. São Paulo: FEA-USP, 1996. Tese de Doutorado.

LIPPITT, Gordon. Quality of Work Life: Organization Renewal in Action. Training ad Development, Alexandria, v.32, n.1, p.4-10, July 1978.

MORAES, Gláucia Therezinha Bardi de. Qualidade de Vida no Trabalho: um estudo sobre prazer e sofrimento em uma multinacional na cidade de Ponta Grossa- PR. Ponta Grossa: Universidade Tecnológica Federal do Paraná, 2006. Dissertação de Mestrado.

MORIN, Estelle M. Os sentidos do trabalho. Revista de Administração de Empresas, São Paulo, v.41, n.3, p. 8-19, jul./set.2001.

OLIVEIRA, Maria das Graças C.O. et. al. Continuidades e descontinuidades das políticas de educação básica: o caso de Pernambuco. Ed. Universitária da UFPE, Recife, 2006.

RODRIGUES, Auro de Jesus. Metodologia Científica. São Paulo. Ed. Avercamp. 2006.

RODRIGUES, Marcus Vinicius. Qualidade de vida no trabalho: evolução e análise no nível gerencial. 12 ed., Petrópolis, RJ. D. Vozes, 2009. 